Review

\title{
Upconversion Nanomaterials: Synthesis, Mechanism, and Applications in Sensing
}

\section{Jiao Chen and Julia Xiaojun Zhao *}

Department of Chemistry, University of North Dakota, Grand Forks, ND 58202, USA;

E-Mail: jiao.chen@my.und.edu

* Author to whom correspondence should be addressed; E-Mail: jzhao@chem.und.edu; Tel.: +1-701-777-3610.

Received: 10 January 2012; in revised form: 13 February 2012 / Accepted: 21 February 2012 / Published: 23 February 2012

\begin{abstract}
Upconversion is an optical process that involves the conversion of lower-energy photons into higher-energy photons. It has been extensively studied since mid-1960s and widely applied in optical devices. Over the past decade, high-quality rare earth-doped upconversion nanoparticles have been successfully synthesized with the rapid development of nanotechnology and are becoming more prominent in biological sciences. The synthesis methods are usually phase-based processes, such as thermal decomposition, hydrothermal reaction, and ionic liquids-based synthesis. The main difference between upconversion nanoparticles and other nanomaterials is that they can emit visible light under near infrared irradiation. The near infrared irradiation leads to low autofluorescence, less scattering and absorption, and deep penetration in biological samples. In this review, the synthesis of upconversion nanoparticles and the mechanisms of upconversion process will be discussed, followed by their applications in different areas, especially in the biological field for biosensing.
\end{abstract}

Keywords: upconversion nanoparticles; biosensing; NIR-radiation

\section{Introduction}

The upconversion phenomenon has been observed in transition metals, actinides, but mainly in the rare earth (RE) elements, which contain the lanthanide (Ln) series, yttrium, and scandium [1]. $\mathrm{Ln}^{3+}$ ions have special $4 \mathrm{f}^{\mathrm{n}} 5 \mathrm{~d}^{0-1}$ inner shell configurations that are well-shielded by outer shells and have 
abundant and unique energy level structures. These $\mathrm{Ln}^{3+}$ ions can exhibit sharp luminescence emissions via intra-4f or $4 \mathrm{f}-5 \mathrm{~d}$ transitions. Their remarkable luminescence properties, such as narrow bandwidth, long-time emission, and anti-Stokes emission, have been widely applied in lasers, solar cells, analytical sensors, optical imaging, photodynamic therapy, and so on. At present, the low luminescence efficiency is one of the main limiting factors. Therefore, to obtain the highest upconversion luminescence efficiency, it is critical to choose an appropriate host material with lower phonon energy (high phonon frequencies of the host lattice lead to nonradiative relaxation). To date, host materials, including fluoride, chloride and bromide, have been shown to enhance upconversion luminescence intensity. Most of chlorides and bromides are sensitive to moisture, and thus are not suitable for labeling biomolecules (used mostly in aqueous solutions) [2]. RE fluorides, mainly $\mathrm{REF}_{3}$ and $\mathrm{AREF}_{4}(\mathrm{~A}=$ alkali), have been considered as an excellent host material due to their high refractive index and high transparency arising from low-energy phonons. These two advantages further lead to low probability of nonradiative decay and increased luminescence quantum yield.

Most fluorescent materials, including dye molecules, quantum dots, and dye-doped silica/gold nanomaterials, emit light by the downconversion process (emitting lower-energy photons under higher-energy irradiation). Although the uses of a conventional organic dye molecule or quantum dot (QD) based biomarker have achieved significant progress in real-time detection and bioimaging, they still have drawbacks. These fluorescent materials are generally excited by ultraviolet (UV) or visible light, which may induce autofluorescence and photodamage to biological samples, resulting in low signal-to-noise ratio and limited sensitivity. These limitations prompted the development of a new type of high-quality and well-shaped nanomaterials known as upconversion nanomaterials (UCNs). These UCNs usually consist of an inorganic host that is doped with $\mathrm{Ln}^{3+}$ ions. They show good biocompatibility and generally low cytotoxicity, and are in fact non-cytotoxic to a broad range of cell lines [3,4]. Furthermore, surface modification by ligand engineering [5-7], ligand attraction [8], surface polymerization [3,9-13], self-assembly [14-16] or layer-by-layer assembly technology [17], broadens their application fields. Surface modification by a silica shell is by far the most popular, common, and practical approach [3,11,18-20]. Proteins, DNA, biological macromolecules or other desirable targets can be easily linked to UCNs. In particular, the UCNs' unique property of emitting visible light under NIR irradiation makes them a suitable candidate both for in vivo and in vitro bioimaging [21-23].

Theoretically, most lanthanide ions can undergo the NIR-to-visible upconversion process; however, relatively efficient upconversion is only possible with a few trivalent lanthanide ions (e.g., $\mathrm{Er}^{3+}$ and $\mathrm{Tm}^{3+}$ ) under low pump densities (980 $\mathrm{nm}$ excitation). Up to now, the most often-used upconversion nanoparticles are $\mathrm{Yb}^{3+}-\mathrm{Er}^{3+}$ or $\mathrm{Yb}^{3+}-\mathrm{Tm}^{3+}$ co-doped $\mathrm{NaYF}_{4}$ nanomaterials $\left(\mathrm{NaYF}_{4}: \mathrm{Yb}^{3+}, \mathrm{Er}^{3+}\right.$ or $\left.\mathrm{NaYF}_{4}: \mathrm{Yb}^{3+}, \mathrm{Tm}^{3+} \mathrm{UCNs}\right)$. In this review, we will briefly discuss the mechanisms of upconversion phenomenon, but mainly focus on the recent progress in UCNs' chemical syntheses and their applications in different areas, especially in the biological field.

\section{Mechanism}

Different upconversion luminescence mechanisms have been recognized either alone or in combination. Three basic mechanisms - excited state absorption (ESA), photon avalanche (PA), and 
energy transfer upconverion (ETU) (also known as addition de photon par transferts d'energies, APTE effect) will be discussed here.

\subsection{Excited State Absorption (ESA)}

ESA involves multistep excitation by sequentially absorbing one or more photons from the ground state to intermediate reservoir stage, and finally populates at excited state, from which upconverison luminescence occurs (Figure 1).

Figure 1. Schematic diagram of excited-state absorption $\left(w^{\prime}>w_{1}, w_{0}\right) . E_{0}, E_{1}$, and $E_{2}$ represent ground state, intermediate, and excited state, respectively. When one ion or electron in the $E_{0}$ state absorbs one photon, it is first excited to the $E_{1}$ state; after sequentially absorbing the second photon, it can jump to the excited state $E_{2}$ and emit higher energy photons when coming back to the ground state.

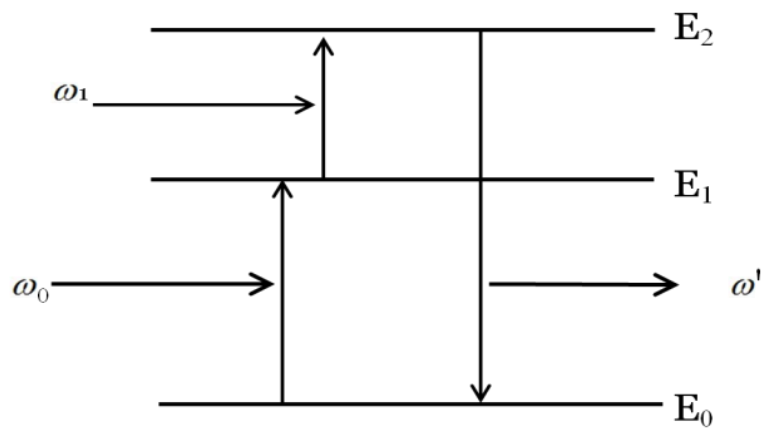

\subsection{Photon Avalanche (PA)}

PA process is a more complex process, which can be characterized by three distinct nonlinear behaviors: transmission, emission, and rise time on the pump power intensity with generally the existence of a critical pump threshold. Take a four-energy system as an example (Figure 2), in which $\mathrm{E}_{0}, \mathrm{E}_{1}$ and $\mathrm{E}_{2}$, and $\mathrm{E}$ represents ground state, intermediate states, and upper excited states, respectively.

Figure 2. Schematic diagram of photon avalanche.

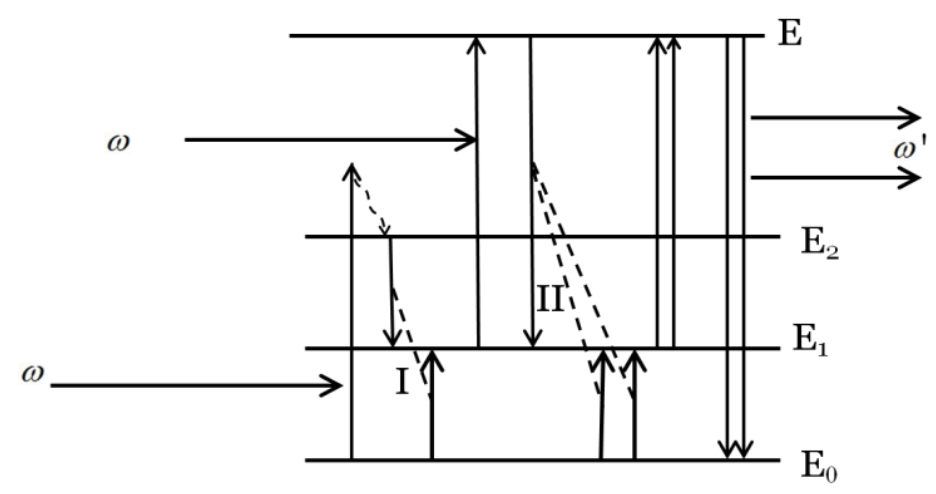

An electron or ion is excited when it absorbs the excitation radiation. The excitation radiation is usually not resonant with the absorption transition from the ground state to the intermediate states, but 
a little higher than $\mathrm{E}_{2}$. Through the cross relaxation, it goes down to $\mathrm{E}_{2}$ state. Energy transfer occurs between the $\mathrm{E}_{2}$ state electron and the $\mathrm{E}_{0}$ state electron, resulting in the formation of two electrons in the $\mathrm{E}_{1}$ state. One of them absorbs the excitation radiation and is excited to the $\mathrm{E}$ state, in which it interacts with $\mathrm{E}_{0}$ state electrons and energy transfer II occurs to form three $\mathrm{E}_{1}$ electrons. Here, the excitation radiation is resonant with the absorption transition from $\mathrm{E}_{1}$ to $\mathrm{E}$. By repeating the whole steps again and again, the number of electrons in the E state increases dramatically. When the electrons go back to the $\mathrm{E}_{0}$ state, high-energy photons are emitted. In summary, the PA process basically involves resonant excited-state absorption, efficient cross relaxation and substantial population of the reservoir level, which leads to strong upconversion emission. Although PA is efficient, it still suffers from some disadvantages, such as limited maximum-output due to the weak ground-state absorption, and high pump powers needed to reach the threshold condition.

\subsection{Energy Transfer Upconversion (ETU)}

ETU is by far the most efficient upconversion process in RE doped nanomaterials and it is independent of the pump power. In the process of ETU, two situations, resonant non-radiative transfer and phonon-assisted non-radiative transfer in two-ion-involved system, will be mainly discussed (Figure 3) [1]. When the excited energies of sensitizer (S) and activator (A) are nearly equal and the distance between them is near enough, energy can be transferred from $\mathrm{S}$ to $\mathrm{A}$, exciting $\mathrm{A}$ from its ground state to excited state before $S$ emits photons. In phonon-assisted non-radiative transfer, an energy mismatch exists between $\mathrm{S}$ and A ions, so phonon assistance is necessary to have the energy transfer process.

Figure 3. Energy transfer processes between two ions: (a) resonant non-radiative transfer; (b) phonon-assisted non-radiative transfer. (S: sensitizer ions, A: activator ions) [1].

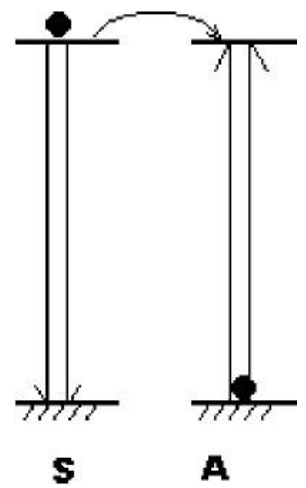

(a)

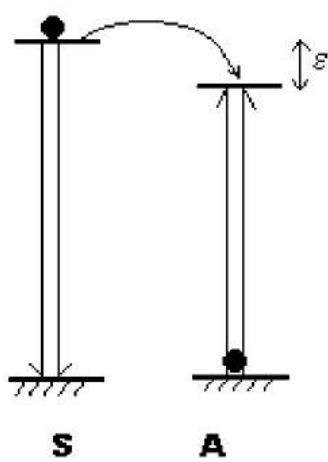

(b)

For example, in the system of $\mathrm{NaYF}_{4}: \mathrm{Yb}^{3+}$ (Figure 4) $\mathrm{Er}^{3+} \mathrm{UCNs}$, red, blue, and green light can be emitted through this process. The $\mathrm{Yb}^{3+}$ ion, with its excited state ${ }^{2} \mathrm{~F}_{5 / 2}$, has an energy comparable to ${ }^{4} \mathrm{I}_{11 / 2}\left(\mathrm{Er}^{3+}\right)$, which can act as a sensitizer for $\mathrm{Er}^{3+}$ and transfer its energy to an unexcited $\mathrm{Er}^{3+}$ ion through the energy transfer process: ${ }^{2} \mathrm{~F}_{5 / 2}\left(\mathrm{Yb}^{3+}\right)+{ }^{4} \mathrm{I}_{15 / 2}\left(\mathrm{Er}^{3+}\right) \rightarrow{ }^{2} \mathrm{~F}_{7 / 2}\left(\mathrm{Yb}^{3+}\right)+{ }^{4} \mathrm{I}_{11 / 2}\left(\mathrm{Er}^{3+}\right)$. By further cross relaxation and phonon-assisted process, red emission $(\sim 654 \mathrm{~nm})$ can be emitted from ${ }^{4} \mathrm{~F}_{9 / 2}\left[{ }^{2} \mathrm{~F}_{5 / 2}\left(\mathrm{Yb}^{3+}\right)+{ }^{4} \mathrm{I}_{13 / 2}\left(\mathrm{Er}^{3+}\right) \rightarrow{ }^{2} \mathrm{~F}_{7 / 2}\left(\mathrm{Yb}^{3+}\right)+{ }^{4} \mathrm{~F}_{9 / 2}\left(\mathrm{Er}^{3+}\right)\right]$. The blue $(\sim 408 \mathrm{~nm})$ and green 
luminescence emissions ( 526 nm and $\sim 533 \mathrm{~nm})$ are emitted from ${ }^{2} \mathrm{H}_{9 / 2}-{ }^{4} \mathrm{I}_{15 / 2}$ and ${ }^{2} \mathrm{H}_{11 / 2}-{ }^{4} \mathrm{I}_{15 / 2}$ (also ${ }^{4} \mathrm{~S}_{3 / 2}-{ }^{4} \mathrm{I}_{15 / 2}$ ) via similar ways, respectively.

Figure 4. Energy diagram of the $\mathrm{Er}^{3+/} \mathrm{Yb}^{3+}$ codoped materials [24].

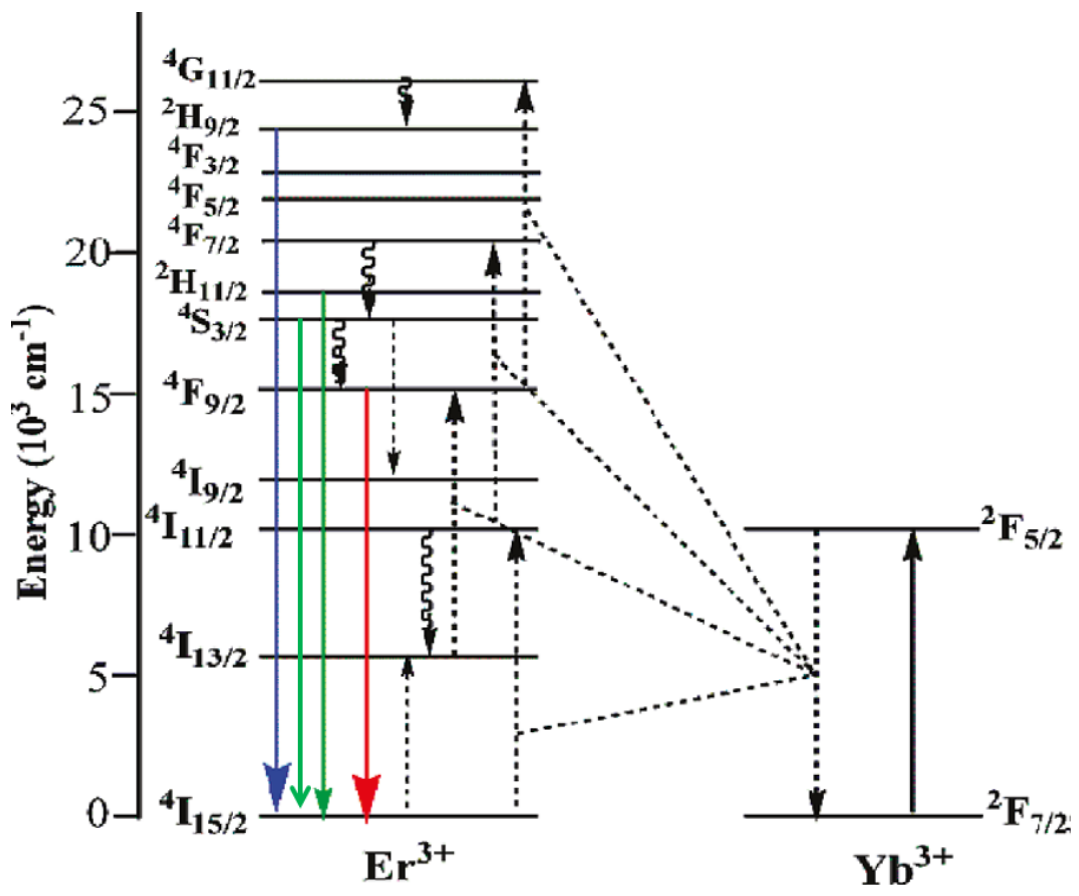

\section{Synthesis of Rare Earth Fluoride Nanomaterials}

In order to obtain high luminescence efficiency, synthesizing high-quality UCNs is very critical. So far, there are three common methods to synthesize UCNs, including thermal decompostition [13,25-30], hydrothermal synthesis [31-33], and ionic liquids-based synthesis [34].

\subsection{Thermal Decomposition Method}

Thermal decomposition, which gives well shaped particles, with good size control, after a relatively short reaction time, is one of the most popular methods. It usually involves dissolving organic precursors in high-boiling organic solvents with the assistance of surfactants. The commonly used organic precursors are trifluoroacetate compounds, and the surfactants typically have polar capping groups and long hydrocarbon chains, such as oleic acid (OA), omeylamine (OM), and 1-octadecence (ODE). Mai et al. [27] systematically investigated the growth mechanism of nanocrystals and pointed out that the trifluoroaetate precursors in hot surfactant solutions went through a unique delayed nucleation pathway. The synthesis reaction was separated as four stages including nucleation in a delayed time, particle growth by monomer supply, size shrinkage by dissolution, and aggregation. Figure 5 illustrates the synthesis steps of $\alpha-\mathrm{NaYF}_{4}: \mathrm{Yb}^{3+}, \mathrm{Er}^{3+} \mathrm{UCNs}$ and by varying the reaction time, concentration of reagents, and reaction temperature, various sizes and shapes of $\mathrm{NaYF}_{4}: \mathrm{Yb}^{3+}, \mathrm{Er}^{3+} \mathrm{UCNs}$ can be obtained. 
Figure 5. Schematic illustration of the growth stages of $\alpha-\mathrm{NaYF}_{4}: \mathrm{Yb}^{3+}, \mathrm{Er}^{3+}$ nanocrystals via a delayed nucleation pathway [27].

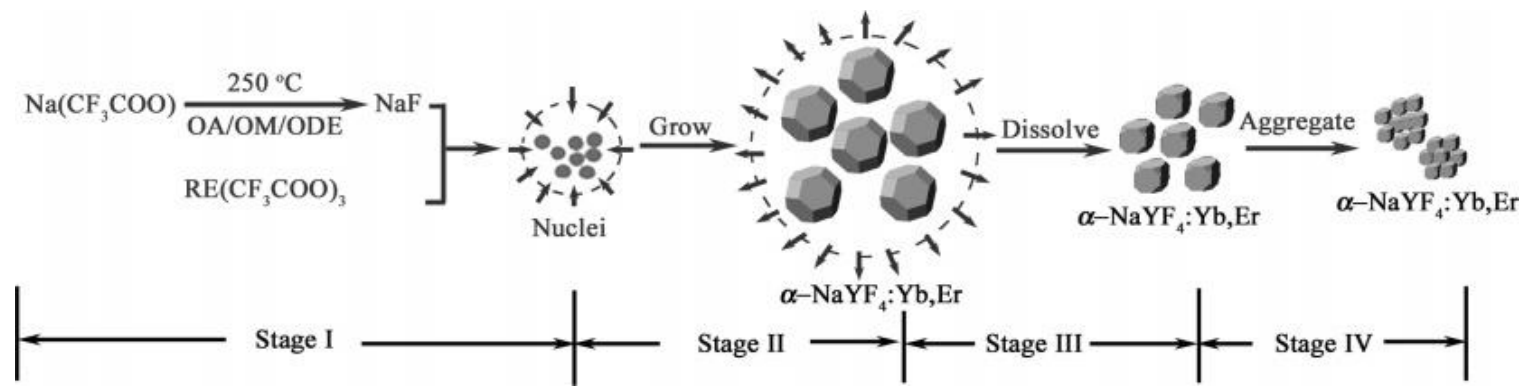

Figure 6 shows a few examples of RE fluoride nanomaterials synthesized by thermal decomposition method, which are well-shaped and monodispersed. Although it gives a narrow size distribution and good shape control, the thermal decomposition method still suffers some drawbacks. It normally requires high reaction temperature $\left(250-330^{\circ} \mathrm{C}\right)$, organic solvents, and an oxygen-free with inert gas protection. In addition, most of the synthesized nanomaterials are stabilized by surfactant, which brings difficulties in the biological applications. Further surface modification is also required.

Figure 6. Representative shapes of various RE fluoride nanomaterials by thermal decomposition method [27,28].

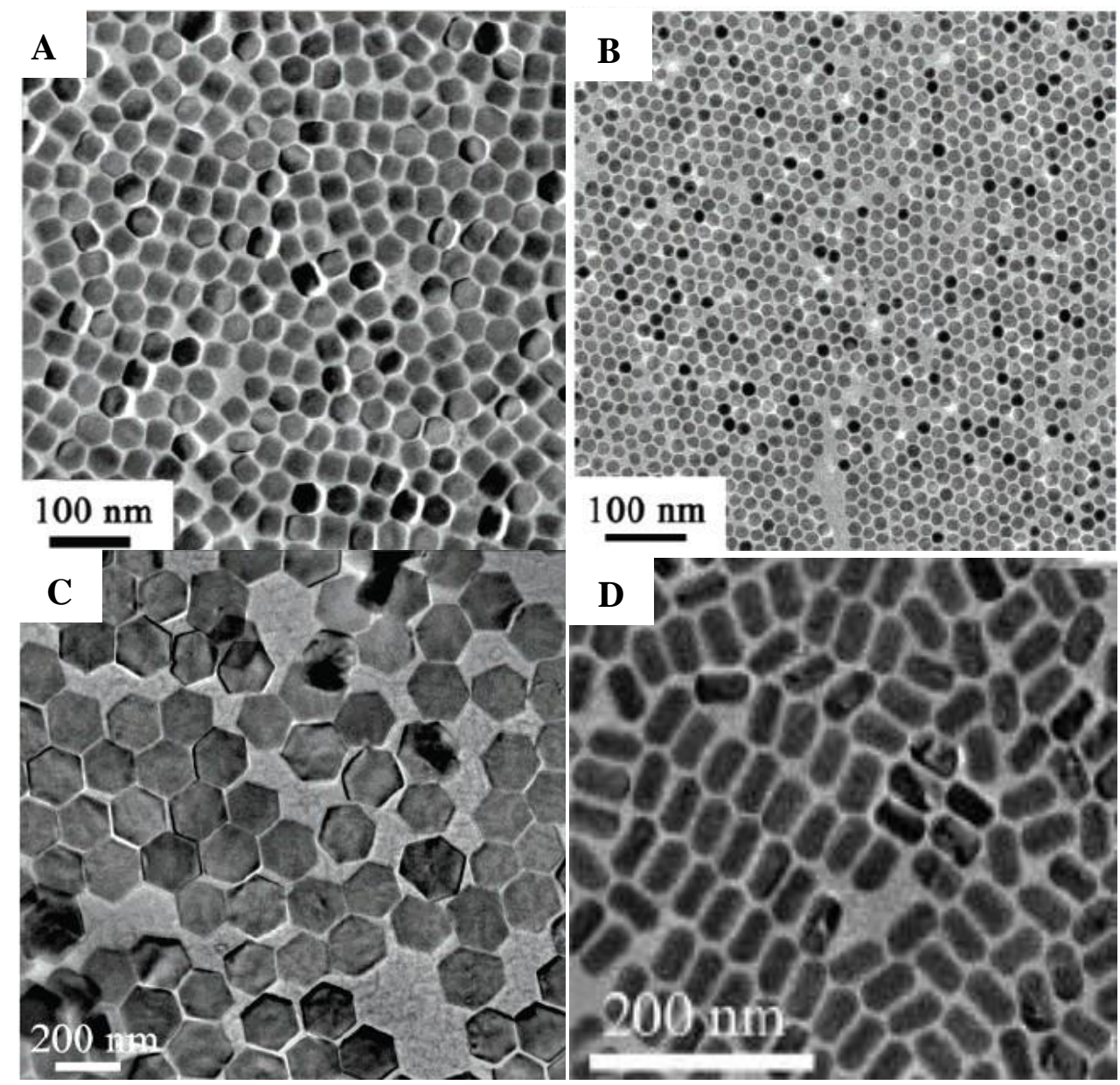




\subsection{Hydrothermal Synthesis Method}

Hydrothermal synthesis is a typical solution-based approach, which is usually employed under high temperatures and pressures $[5,31,35,36]$. Unlike the thermal decomposition method, which can only use an organic compound as a solvent, hydrothermal synthesis can occur in a water-based system and at a lower reaction temperature $\left(160-220^{\circ} \mathrm{C}\right)$ in a relatively environmentally friendly approach. It is an effective and convenient process in preparing inorganic materials with diverse controllable morphologies and architectures. For example, various shapes of hexagonal $\mathrm{NaYF}_{4}$ crystals, such as prism, disk, tube, rod, and octadecahedral shapes were synthesized by applying this method [37,38]. Recently, in Lin's group, the mechanism of synthesizing different shapes of RE fluoride nano-/microcrystals was systematically investigated [33]. It was reported that the organic additive trisodium citrate, the fluoride source, and $\mathrm{pH}$ value have great effects on the shapes (Figure 7).

Figure 7. Different shapes of RE fluoride nano-/microcrystals by hydrothermal method [37-39].
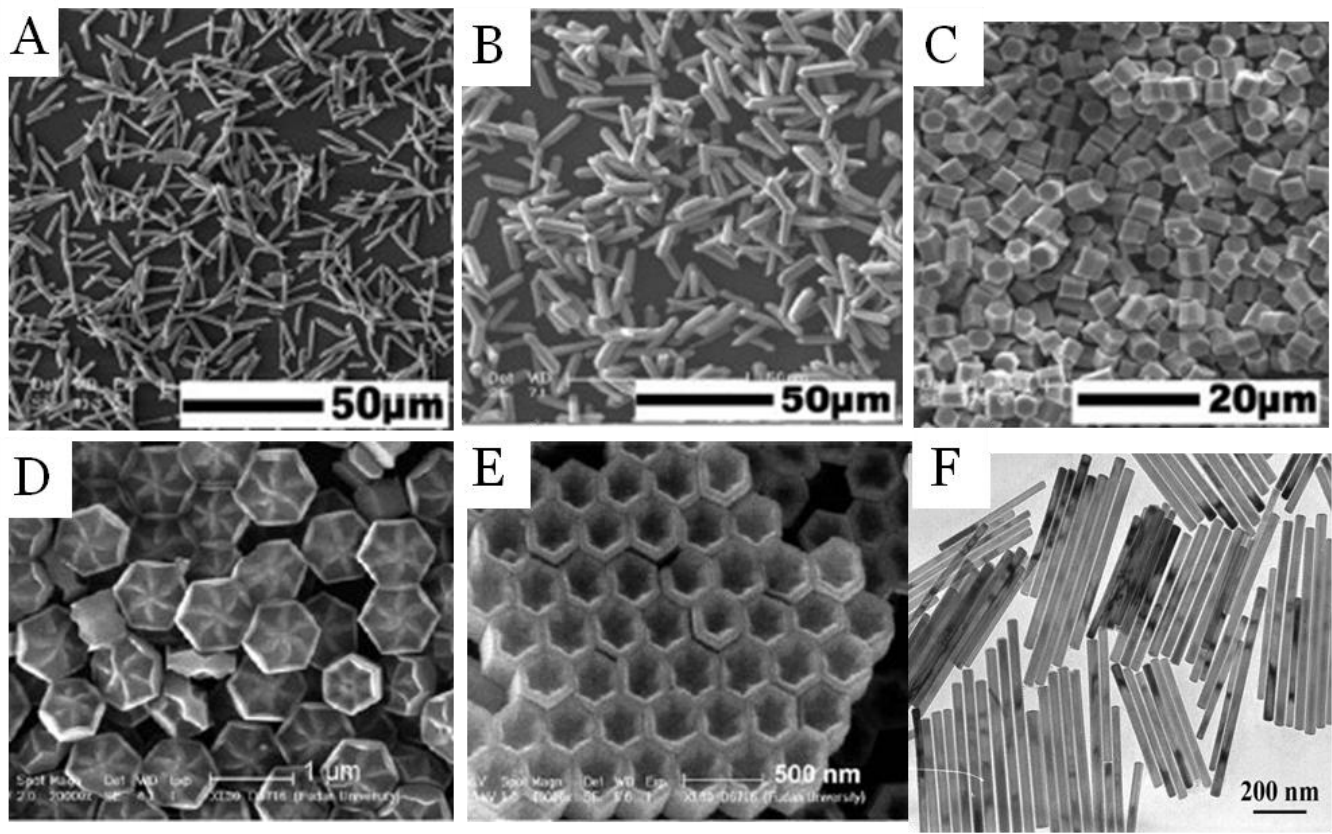

\subsection{Ionic Liquids-Based Synthesis Method}

Compared to the other two methods, ionic liquids-based synthesis is a relatively green method due to not needing organic solvents, low reaction temperature, and a short reaction time. Nanomaterials are synthesized in ionic liquid media, which are known as "green solvents" because of their chemical stability, low vapor pressure, and non-flammability. However, the synthesized nanomaterials are of a lower quality with a broader size distribution, lower monodispersity, and less uniformity when compared with other two methods [40], which limits their applications.

Therefore, the thermal decomposition and hydrothermal synthesis methods are still the most widely used and best methods for producing well-controlled shapes and sizes of RE fluoride nanomaterials. 


\section{Properties and Applications}

There has been a growing interest in studying the upconveriosn phenomenon after it was first recognized in the mid-1960s. It has been widely used in solid-state lasers (especially blue-light-emitting lasers) [41], solar cells [42,43], and waveguide amplifiers [44,45]. It was not considered to be used in the biological field until the tremendous advances in nanotechnology over the last decade. The successful synthesis of high-quality, lanthanide-doped upconversion nanomaterials (UCN) have broadened their applications. Nondestructive optical memory [46] and rewritable optical storage [47] applications based on UCNs have been developed recently. Furthermore, these UCNs with their controllable sizes and unique luminescence properties have become prominent in the biological field as promising alternatives to conventional organic dyes and quantum dots (QDs). Compared to organic dyes and QDs, UCNs have high quantum yields, long lifetimes, high photostability, a narrow emission peak, and most importantly, low optical background noise due to the absence of autofluorescence under NIR radiation. Multiple analytes can be detected simultaneously from different UCNs excited by the same IR laser [48]. Furthermore, their applications in biolabeling [6,10,25,49], homogeneous assay [11,50,51], and as reporters for DNA microarrays [52] have been extensively studied. Since these UCNs need to be used in cells or animals, the toxicity study is also very important. Therefore, their viability will now be discussed, followed with their applications in the biological field, including photodynamic therapy, imaging, and others. The recent advances of these UCNs in other fields will be discussed as well.

\subsection{Toxicity}

Due to the rapid progress in developing UCNs' applications in the biological field, the safety and toxicity of UCNs are a growing concern and extremely important. The most common methods to evaluate the toxicity are through cellular morphology and mitochondrial function, such as methylthiazolyl tetrazolium (MTT) and 3-(4,5-dimethylthiazol-2-yl)-5-(3-carboxymethoxyphenyl)-2-(4sulfophenyl)-2H-tetrazolium (MTS) assays. Studies have shown that UCNs are non-/low-toxicity to a broad range of cell lines $[4,6,10,18,53,54]$. The cells were usually treated with different concentrations of UCNs for various time range, and by measuring the cell viability percentage, the UCNs toxicity was determined. For example, in Zhang's group, they studied both polyethyleneimine (PEI) [55] and silica-coated [18] UCNs' cell toxicity. In the case of silica-coated UCNs, although the cell viability decreased as a function of both concentration and time, $93.4 \%$ of skeletal myoblast cells and $93.2 \%$ of BMSCs cells were still alive under $24 \mathrm{~h}$ incubation at a concentration of $1 \mu \mathrm{g} / \mathrm{mL}$, which indicated great biocompatibility [18]. Recently, Li and co-workers investigated the UCNs' long-term in vivo distribution and toxicity [56]. Their findings show that the mice survived for 115 days after the intravenously injection $15 \mathrm{mg} / \mathrm{kg}$ of UCNs with no apparent adverse effects observed to their health, indicating the possibility for long-term targeted imaging and therapy studies in vivo. Hu et al. treated the KB cells with different concentrations of PEG-modificed UCNs (Figure 8) [6]. Even at a high concentration of $250 \mu \mathrm{g} / \mathrm{mL}$, the cell viability still remained above $80 \%$, showing the low cytotoxicity of the nanoparticles. 
Figure 8. In vivo cell viability of $\mathrm{KB}$ cells incubated with mPEG-UCNPs at different concentrations for 4-12 h [6].

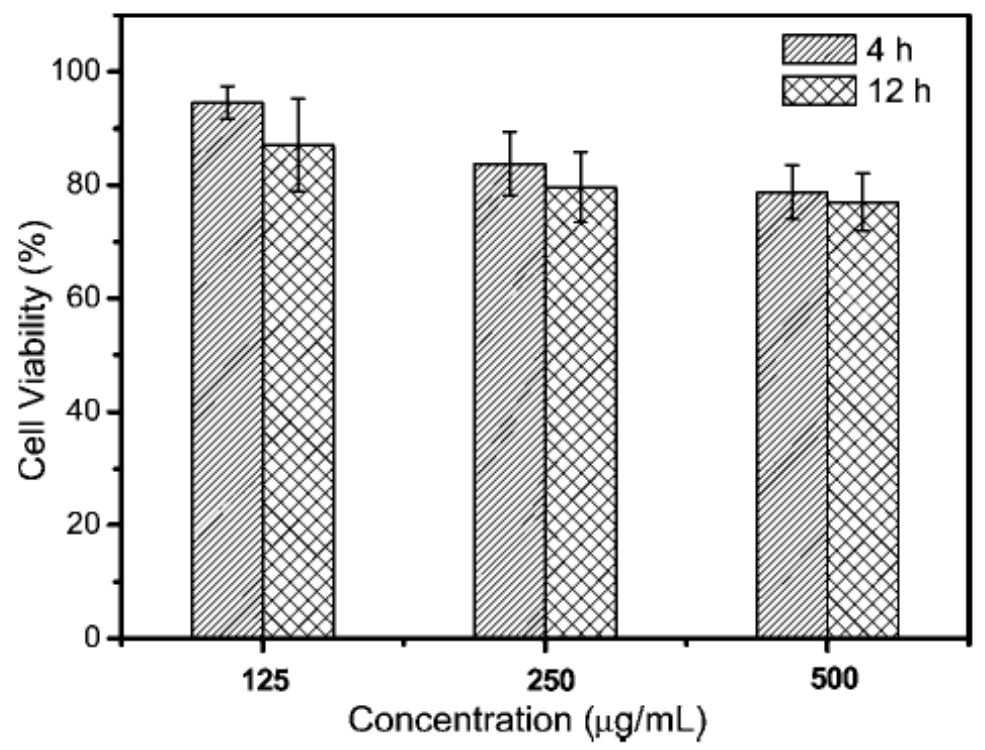

\subsection{Applications in Cancer Therapy}

Light has been used to treat various diseases for more than 3,000 years in many countries, such as Ancient Egypt, India, and China [57,58]. More than 100 years ago, Oscar Raab, a German medical student, accidently observed a combination of light and acridine could induce cell death. This was later named as a "photodynamic action" [59]. Photodynamic therapy (PDT) was not approved until 1993 in Canada, where Photofrin was used as a photosensitizer for bladder cancer treatment. A typical PDT process requires three elements: light, photosensitizer, and oxygen. When the photosensitizer is irradiated under certain wavelength, it will be excited from the ground state to the excited state. The energy is released when it returns to the ground state, which is transferred to the nearby oxygen to generate reactive oxygen species (ROS, like singlet oxygen, ${ }^{1} \mathrm{O}_{2}$ ). ROS can cause oxidative damage to nearby cells and ultimately kill the cells $[60,61]$. PDT, as a cancer therapy, has become a popular and acceptable technique in recent years $[62,63]$ due to a better selectivity for the tumor and a lower systemic toxicity for fewer side effects compared to radiation therapy and chemotherapy $[64,65]$. Some nanomaterials, such as gold nanomaterials [66-68], QDs [69-73], and polymers [74], have been employed in PDT. However, most of them are through the downconversion luminescence, which needs high energy to activate the photosensitizers. Furthermore, the light needed to activate photosensitizers only can penetrate about a centimeter and can cause normal cell death as well. Their inherent cytoxicity (like QDs), downconversion luminescence property and limited penetration depth all cause hindrances in the further applications in biomedical field. Therefore, it is important to find a better way with high PDT efficiency, deeper penetration, and less side effects.

UCN satisfies all the requirements due to its deeper penetration (capable of converting NIR light into visible light), lower toxicity, higher stability, and easier surface modification. UCNs used in PDT are usually pre-coated with a shell, which has the functions of: (1) doping matrix for photosensitizers; (2) specific target on tumor cells; and (3) UCNs stabilization. The $\mathrm{NaYF}_{4}: \mathrm{Yb} / \mathrm{Er} \mathrm{UCN}$ is one of the most common used UCN in PDT due to its high UC efficiency [19,75-77]. Zhang and co-workers first 
demonstrated a novel design for PDT based on UCNs for the treatment of bladder cancer cells (Figure 9) [78]. UCNs were coated with a layer of mesoporous silica shell, in which the photosensitizers were doped. An antibody, which had specific antigens that were expressed on the target cell's surface, was covalently attached on the surface of the silica shell. Due to the spectra overlap between photosensitizers' absorbance and UCNs' emission, the photosensitizer-doped UCNs can generate ${ }^{1} \mathrm{O}_{2}$ under NIR irradiation and further kill the target cells. The generation of ${ }^{1} \mathrm{O}_{2}$ is usually indicated by the quenching phenomenon of ABDA or ADPA.

Figure 9. Schematic of the design of the versatile photosensitizer based on UCNs [78].

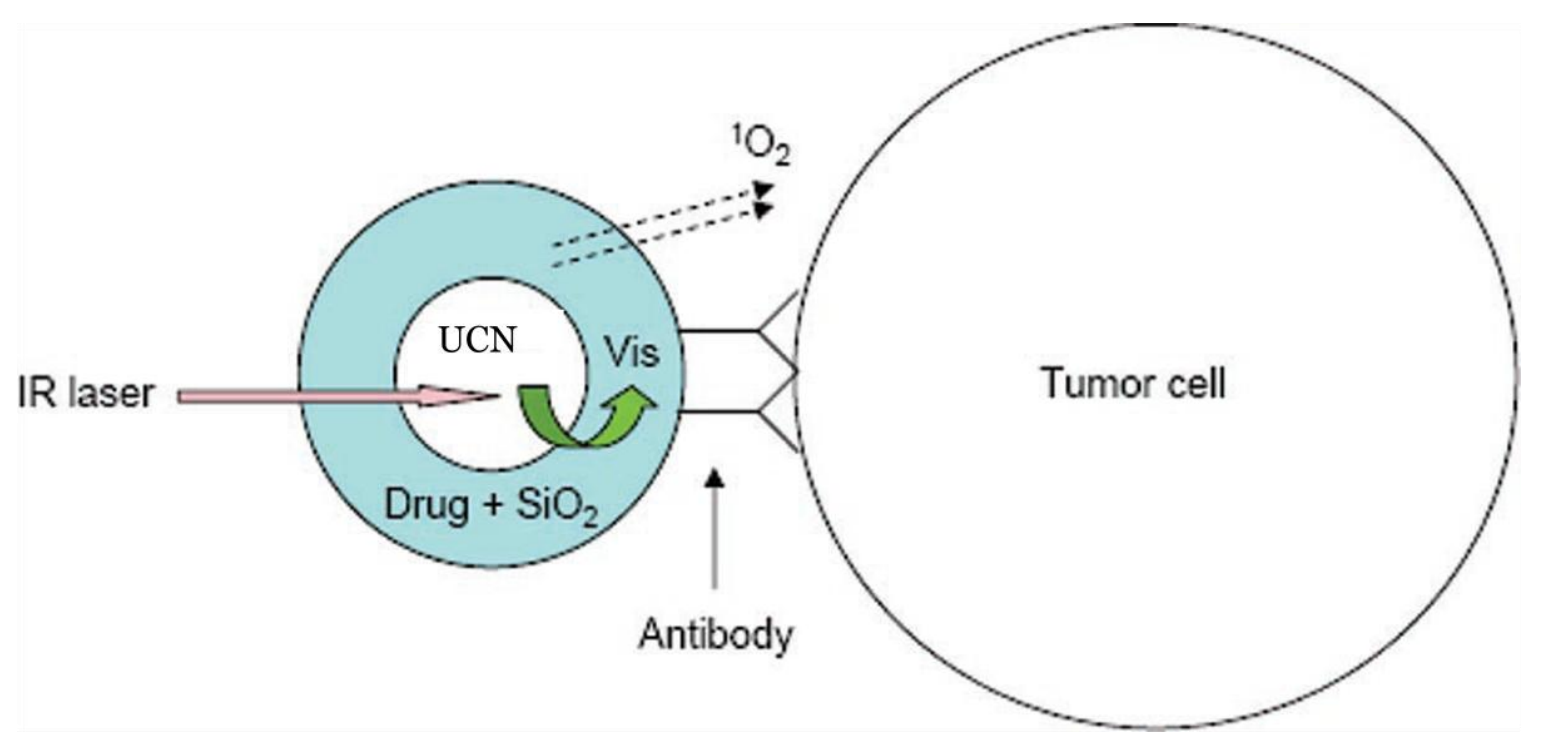

Zhang et al. applied similar principle to study PDT effect on cancer cells [77]. One thin layer of silica was coated on UCNs, followed by second layer of mesoporous silica, which was further doped with photosensitizers. The photosensitizers doped in the silica matrix can be protected from degradation in the harsh biological environment but the formed singlet oxygen can still be released. The obtained fluorescence image showed the uptake of mesoporous silica coated UCNs by murine bladder cancer cells under the excitation of $980 \mathrm{~nm}$. The significance cell viability difference between photosensitizer-doped UCNs and no-photosensitizer UCNs was observed when both were exposed to NIR laser only for $5 \mathrm{~min}$, indicating the production of singlet oxygen.

\subsection{Applications in Optical Imaging}

Optical imaging has become an essential tool in biological research and clinical application due to its ability of visualizing morphological details in tissue. Although traditional optical imaging has been widely used in in vivo and in vitro imaging with a combination of different functional nanoparticles, it suffers some inherent limitations such as significant auto-fluorescence from biological tissues, short penetration depth ability, and causing DNA damage or cell death [33,79-83]. These limitations occur because most of them are based on conventional downconversion phenomena, emitting low-energy fluorescence when excited by a high-energy light (usually UV or visible light). Therefore, finding an appropriate alternative, which has low background signal but also deep penetration ability, is very important. 
The $\mathrm{Ln}^{3+}$-doped materials were first used in tissue imaging in 1999, where Zijlmans et al. observed a low autofluorescence signal and no bleaching even after continuous exposure to high excitation energy levels [48]. However, the size of the applied particles was in the level of submicron size, which limited the applications. In recent years, with the rapid development of synthesis techniques, smaller size but with high-quality UCNs are easily obtained. The UCNs-based imaging technique has been explored and widely used in cell, tissue, and animal imaging [12,48,84-89]. Wu and co-workers [90] have recently shown that UCNs can be used for single-molecule imaging and the individual UCNs were bright enough to be imaged with a modest-power CW laser. The high photostability of the UCNs was also observed even after more than $1 \mathrm{~h}$ of continuous laser illumination, implying the extraordinary ability of UCNs for long-period observation of cells. Another bioimaging advantage of UCNs is their low background fluorescence and high signal-to-noise ratio.

Lim et al. [22,53] performed in vivo and scanning electron microscopy imaging of UCNs in C. elegans due to its short life cycle, rapid growth, and appropriate size to optical microscopy. In their study, $C$. elegans were fed with UCNs and imaged at fixed time intervals in order to track the movement of the phosphors through their digestive system. No significant change in the phosphors was monitored up to $24 \mathrm{~h}$ and after feeding the worms with food (Figure 10), the phosphors were secreted in under $2 \mathrm{~h}$. It demonstrated that UCNs were nonbleaching, biocompatible, and nontoxic, which make them ideal candidates in the biological system.

Figure 10. False color two-photon images of C. elegans at $980 \mathrm{~nm}$ excitation with red representing the bright field and green for the phosphor emission. (Left) The worms were deprived of food over a period of $24 \mathrm{~h}$, showing little or no change at (a) $0 \mathrm{~h}$, (b) $4 \mathrm{~h}$, and (c) 24 h. (Right) The worms were given food immediately after being fed with phosphors,

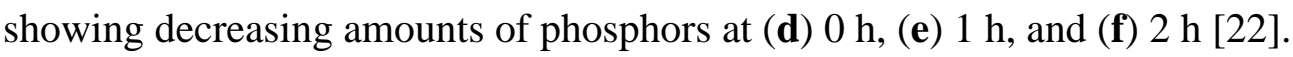

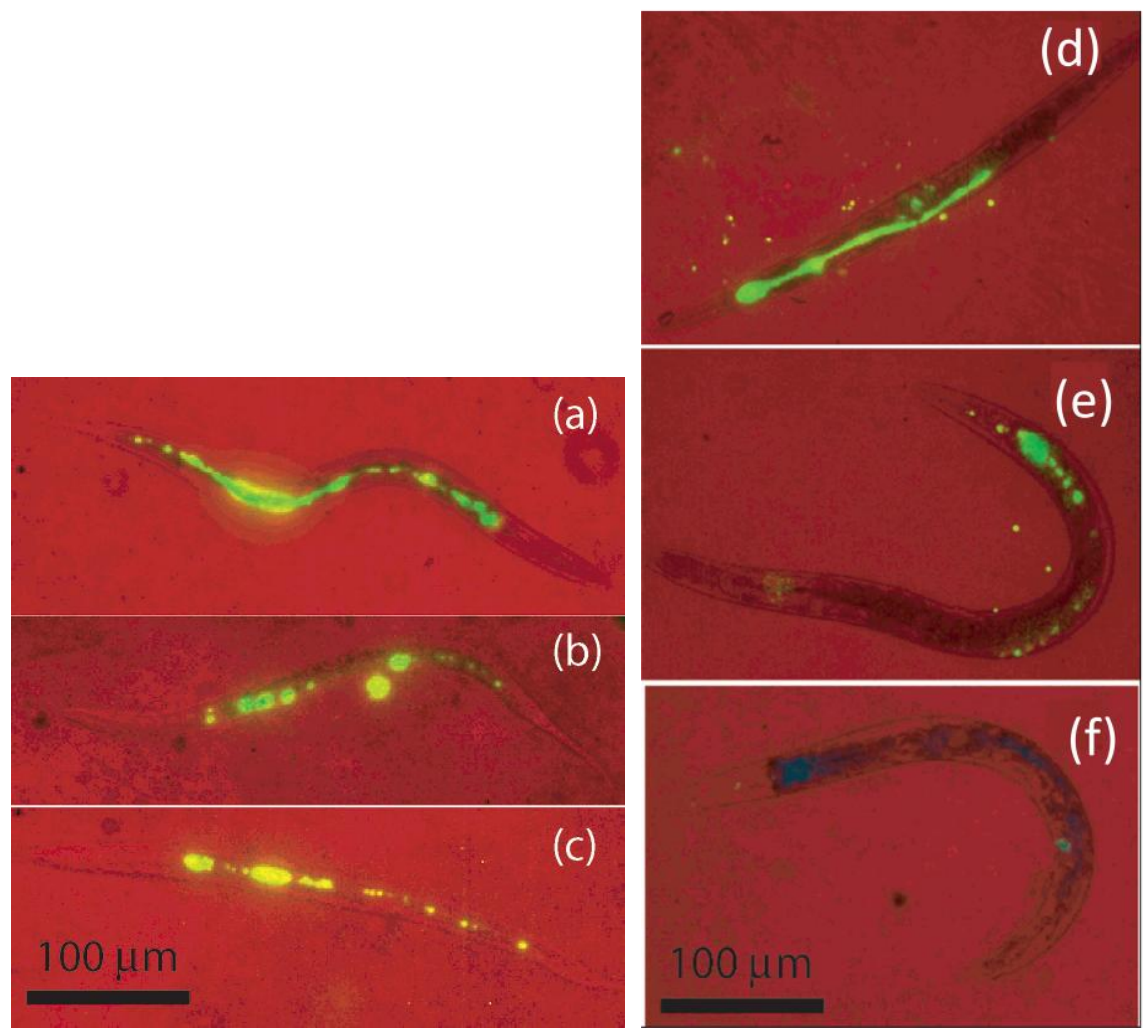


Since Chatterjee et al. [55] first studied the in vivo imaging of UCNs in small mammals which showed much higher fluorescence compared to QDs, it has made significant progress and attracted great interest. In Li's group [4], they found a high relaxivity of $5.60 \mathrm{~s}^{-1}(\mathrm{mM})^{-1}$ of UCNs, and the UCNs were successfully applied as contrast agents form magnetic resonance imaging (MRI) in vivo. The concept of upconversion and magnetic resonance dual-modality imaging in vivo of whole-body animals using UCNs with magnetic resonance properties has showed great promise to serve as a platform technology for the next-generation of probes for bioimaging in vivo. Fluorescence targeted imaging in vivo has proven very useful in tumor recognition and drug delivery. Xiong et al. [23] developed a high contrast upconversion imaging protocol based on UCNs as luminescent labels for targeted imaging of tumors both in in vivo and in vitro. No autofluorescence signal observed in imaging even at high penetration depth $(\sim 600 \mu \mathrm{m})$ and the signal-to-noise ratio could be reached $\sim 24$ between the tumor and the background, which cannot be obtained in single-photon or two-photon fluorescence imaging (Figure 11). Their study may open up a new perspective for cell recognition and targeted imaging-guided cancer diagnosis.

Figure 11. Time-dependent in vivo upconversion luminescence imaging of subcutaneous U87MG tumor (left hind leg, indicated by short arrows and MCF-7 tumor (right hind leg, indicated by long arrows) borne by athymic nude mice after intravenous injection of UCN-RGD over a $24 \mathrm{~h}$ period. (H) The in vivo signal-to-noise ratio (SNR) calculation. Region of interest (ROI)1, specific uptake; ROI 2, nonspecific uptake; ROI 3, background. $\mathrm{SNR}=($ IROI $1-$ IROI 3)/(IROI $2-$ I ROI 3) [23].

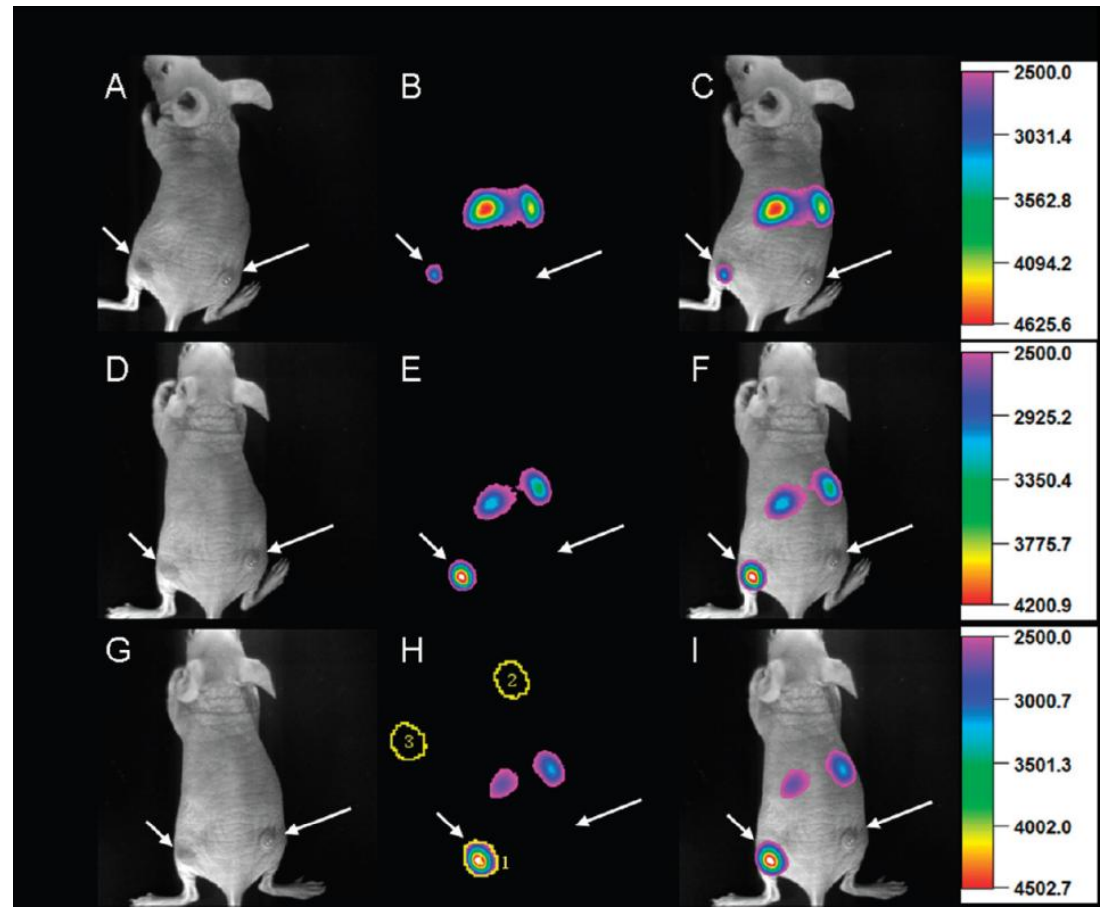

The ability to manipulate color output of nanomaterials can broaden their applications, especially in the case of multiplexed biological labeling and imaging. Various approaches, based on surface plasmon resonance [91-94] or using multicolor-encoded microbeads and nanoparticles [95,96], have been applied to tune multicolor output. However, most of these methods need high energy excitation 
source in the UV region, which bring limitations to bioimaging studies due to the significant background (autofluorescence) and photo damage to the samples. The UCNs-based method becomes extremely promising to solve these problems, and a few current researchers have already shown the possibility to output multicolor lights. It can be obtained by adjusting the reaction temperature and time, crystal structure and phase, or changing the combinations of $\mathrm{Ln}^{3+}$ dopants and dopant concentration (Figure 12) [26,39,83,97,98]. Ehlert et al. presented that four different colors of UCNs can be spectrally separated under multiplexing conditions with a single excitation source of $980 \mathrm{~nm} \mathrm{[99].} \mathrm{Li}$ and co-workers obtained the multicolor output signal by encapsulating organic dyes or QDs into the silica shell and the upconversion fluorescence was generated based on FRET from the UCN-cores to organic dyes or QDs [100].

Figure 12. Room temperature upconversion emission spectra of (a) $\mathrm{NaYF}_{4}: \mathrm{Yb} / \mathrm{Er}$ (18/2 mol\%), (b) $\mathrm{NaYF}_{4}: \mathrm{Yb} / \mathrm{Tm}(20 / 0.2 \mathrm{~mol} \%)$, (c) $\mathrm{NaYF}_{4}: \mathrm{Yb} / \mathrm{Er}(25-60 / 2 \mathrm{~mol} \%)$, and (d) $\mathrm{NaYF}_{4}: \mathrm{Yb} / \mathrm{Tm} / \mathrm{Er}(20 / 0.2 / 0.2-1.5 \mathrm{~mol} \%)$ particles in ethanol solutions. The spectra in (c) and (d) were normalized to $\mathrm{Er}^{3+} 650 \mathrm{~nm}$ and $\mathrm{Tm}^{3+} 480$ emissions, respectively. Compiled luminescent photos showing corresponding colloidal solutions of (e) $\mathrm{NaYF}_{4}: \mathrm{Yb} / \mathrm{Tm}$ (20/0.2 mol\%), (f-j) $\mathrm{NaYF}_{4}: \mathrm{Yb} / \mathrm{Tm} / \mathrm{Er}(20 / 0.2 / 0.2-1.5 \mathrm{~mol} \%)$, and (k-n) $\mathrm{NaYF}_{4}: \mathrm{Yb} / \mathrm{Er}$ $(18-60 / 2 \mathrm{~mol} \%)$. The samples were excited at $980 \mathrm{~nm}$ with a $600 \mathrm{~mW}$ diode laser [83].

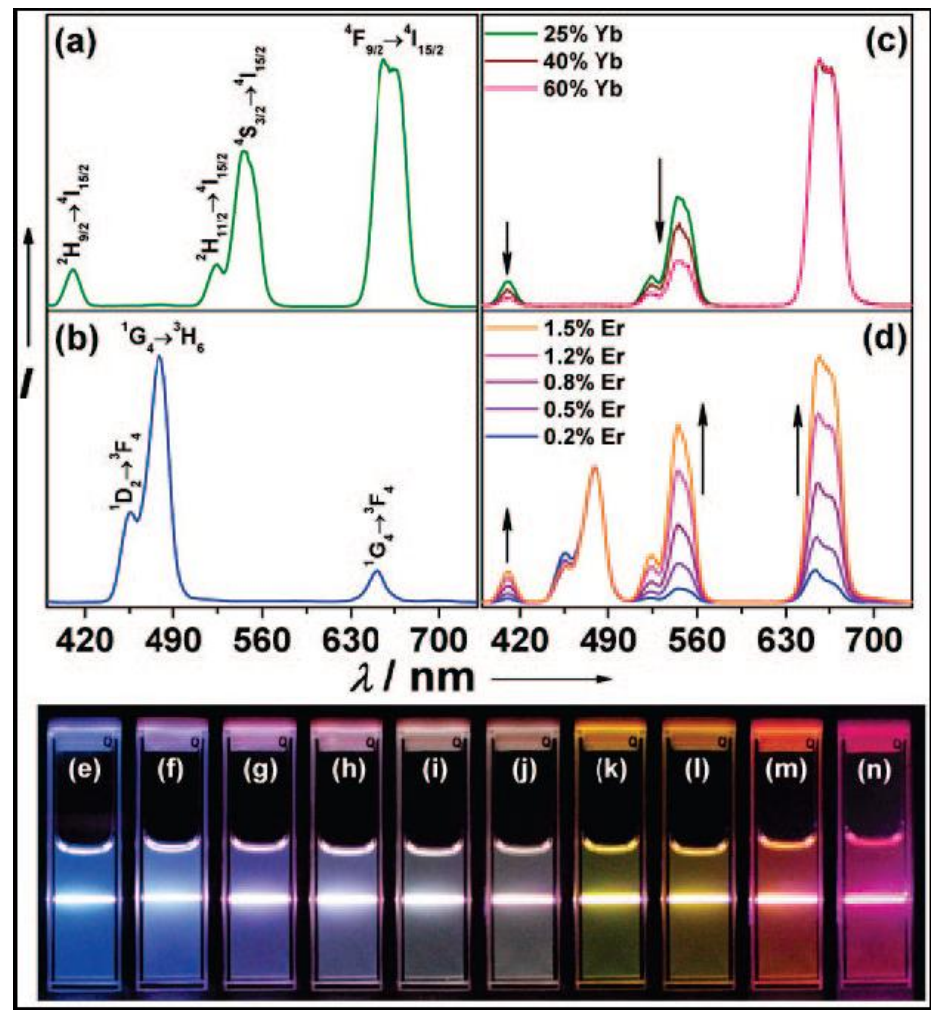

The emission efficiency can further be enhanced by combining with other metal nanoparticles [12,101], surface modification [102], and multiple $\mathrm{Ln}^{2+}$ ions in the UCNs [103]. Chen et al. recently found that by simply increasing the content of the doped $\mathrm{Yb}^{3+}$ ions from 20 to $100 \%$, their NIR-to-NIR upconversion photoluminescence intensity increased about 8.6 times per $\mathrm{Yb}^{3+}$ concentration and 43 times per nanoparticle [104]. 


\subsection{Applications in Sensors}

DNA/RNA analysis is of great importance in molecular biology, genetic, and molecular medicine. Great effects have been invested in the precise concentration detection, such as metal nanoparticle-based analysis [105-108]. In recent years, UCNs were also used for the sensitive detection of oligonucleotides. For example, van de Rijke et al. [52] and Corstjens et al. [109] used UCNs as direct labeling reagents to detect single strand nucleic acids. A new design of a nucleotide sensor by Zhang et al. [110] used $\mathrm{UCN}$ as energy donor and the other fluorophore as an energy acceptor in a sandwich assay format (Figure 13). In the presence of UCNs and IR irradiation, the fluorophore was brought close to the UCN and energy transfer took place, leading to the light emission from the fluorophore. The target oligonucleotide can be detected by monitoring the fluorophore emission. This sensor displayed high sensitivity $(1.3 \mathrm{nM})$, high specificity, and self-calibration capability. A general aptasensor for detection of various target molecules was reported recently by Liu et al. [111], which was based on UCNs-graphene oxide FRET. This proposed design can be further extended for sensing other kinds of molecules as well as causing structure conformations of ssDNA, which have shown its great potential in clinical diagnostic and biosensing techniques.

Figure 13. The schematic of the nucleotide sensor design [110].

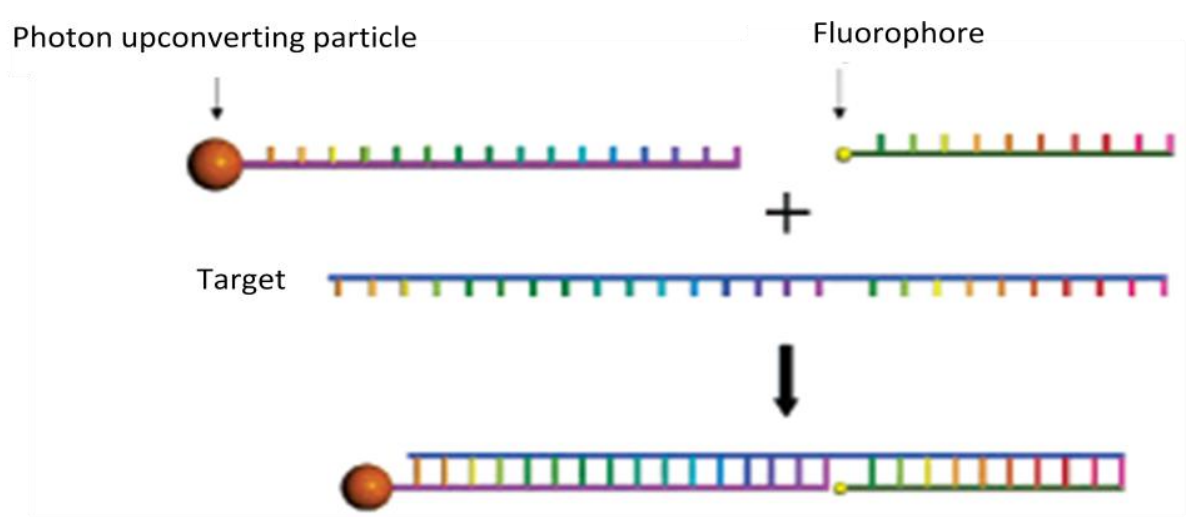

The UCNs-based sensors are used not only in the biological field, but also in the chemical area. Mader et al. [112] developed an ammonia sensor based on the use of UCNs and the pH probe phenol red immobilized in a polystyrene matrix. In the presence of ammonia, a strong increase in the $560 \mathrm{~nm}$ absoption of the $\mathrm{pH}$ probe caused the green emission of the UCNs to be screened off, while the red emission of the UCNs remained unaffected. The ratio of the intensities of the green emissions and the red emission of the UCNs served as the detection signal. Achatz et al. [113] first developed an oxygen sensor by using UCNs as the nanolamps. In the sensing method they presented, the UCNs were used as light source that can cause photoexcitation of an iridium (III) complex. The fluorescence of this complex was dynamically quenched by oxygen. Most recently, Li et al. [114] described a highly selective and sensitive $\mathrm{CN}^{-}$sensor by using the chromophoric iridium (III) complex-coated upconversion nanoparticles. It is the first time that the developed sensor can be used for both bioimaging of an anion in living cells and sensing. This novel $\mathrm{CN}^{-}$sensor can provide a very low detection limit of $0.18 \mu \mathrm{M}$ in the aqueous solution. Also, a chromophoric rughenium complex-assembled upconversion nanophosphor was developed and used as a $\mathrm{Hg}^{2+}$ sensor by Li's group [115]. The $\mathrm{Hg}^{2+}$ nanoprobe showed its 
capability of not only monitoring the concentration of $\mathrm{Hg}^{2+}$ but also monitoring changes in the distribution of $\mathrm{Hg}^{2+}$ in living cells by upconversion luminescence bioimaging.

\section{Conclusions}

In this review, the mechanism of upconversion phenomenon, the UCNs' unique luminescence properties, and the recent advances in UCNs' chemical synthesis and applications were highlighted. Great progress in size, shape, and phase control of UCNs has been achieved by using various synthesis methods, which also has dramatically broadened their applications in the biological field. In addition to their successful applications in biological labels and fluorescence imaging, they also attracted increasing attention in cancer therapy (mainly focus on PDT). However, there are still some limitations to overcome. First, the synthesized UCNs are normally not water soluble. The one-pot synthesis of water-soluble UCNs always results in broad size distribution and poor shape. Although surface modification can enhance their water solubility and biocompatibility, the procedures are time-consuming and may affect the luminescence efficiency. Secondly, the UCNs-based PDT is still in its infancy. The questions of how to load enough photosensitizers without changing the size significantly, and how to bind the photosensitize-loaded UCNs more specifically to cancer cells still need to be addressed. We believe UCNs-based techniques will be widely exploited and will solve some of today's most challenging problems.

\section{Acknowledgements}

The work was supported by the National Science Foundation Grant CHE-0911472 and CHE0947043, and the U.S. Environmental Protection Agency Grant SU-83508601.

\section{References}

1. Auzel, F. Upconversion and anti-stokes processes with $\mathrm{f}$ and $\mathrm{d}$ ions in solids. Chem. Rev. 2004, 104, 139-174.

2. Egger, P.; Rogin, P.; Riedener, T.; Gudel, H.U.; Wickleder, M.; Hulliger, J. $\mathrm{Ba}_{2} \mathrm{ErCl}_{7}-\mathrm{A}$ new near IR to UV upconversion material. Adv. Mater. 1996, 8, 668-672.

3. Yang, J.; Deng, Y.; Wu, Q.; Zhou, J.; Bao, H.; Li, Q.; Zhang, F.; Li, F.; Tu, B.; Zhao, D. Mesoporous silica encapsulating upconversion luminescence rare-earth fluoride nanorods for secondary excitation. Langmuir 2010, 26, 8850-8856.

4. Zhou, J.; Sun, Y.; Du, X.; Xiong, L.; Hu, H.; Li, F. Dual-modality in vivo imaging using rare-earth nanocrystals with near-infrared to near-infrared (NIR-to-NIR) upconversion luminescence and magnetic resonance properties. Biomaterials 2010, 31, 3287-3295.

5. Cao, T.; Yang, Y.; Gao, Y.; Zhou, J.; Li, Z.; Li, F. High-quality water-soluble and surface-functionalized upconversion nanocrystals as luminescent probes for bioimaging. Biomaterials 2011, 32, 2959-2968.

6. Hu, H.; Yu, M.; Li, F.; Chen, Z.; Gao, X.; Xiong, L.; Huang, C. Facile epoxidation strategy for producing amphiphilic up-converting rare-earth nanophosphors as biological labels. Chem. Mater. 2008, 20, 7003-7009. 
7. Naccache, R.; Vetrone, F.; Mahalingam, V.; Cuccia, L.A.; Capobianco, J.A. Controlled synthesis and water dispersibility of hexagonal phase $\mathrm{NaGdF}_{4}: \mathrm{Ho}^{3+} / \mathrm{Yb}^{3+}$ nanoparticles. Chem. Mater. 2009, 21, 717-723.

8. Yi, G.; Chow, G.M. Water-soluble $\mathrm{NaYF}_{4}: \mathrm{Yb}, \operatorname{Er}(\mathrm{Tm}) / \mathrm{NaYF}_{4} /$ polymer core/shell/shell nanoparticles with significant enhancement of upconversion fluorescence. Chem. Mater. 2007, 19, 341-343.

9. Hu, H.; Xiong, L.; Zhou, J.; Li, F.; Cao, T.; Huang, C. Multimodal-luminescence core-shell nanocomposites for targeted imaging of tumor cells. Chem. Eur. J. 2009, 15, 3577-3584.

10. Jiang, S.; Zhang, Y.; Lim, K.M.; Sim, E.K.W.; Ye, L. NIR-to-visible upconversion nanoparticles for fluorescent labeling and targeted delivery of siRNA. Nanotechnology 2009, 20, 155101-155110.

11. Jiang, S.; Zhang, Y. Upconversion nanoparticle-based FRET system for study of siRNA in live cells. Langmuir 2010, 26, 6689-6694.

12. Zhang, F.; Braun, G.B.; Shi, Y.; Zhang, Y.; Sun, X.; Reich, N.O.; Zhao, D.; Stucky, G. Fabrication of $\mathrm{Ag} @ \mathrm{SiO}_{2} @ \mathrm{Y}_{2} \mathrm{O}_{3}$ : Er nanostructures for bioimaging: Tuning of the upconversion fluorescence with silver nanoparticles. J. Am. Chem. Soc. 2010, 132, 2850-2851.

13. Li, Z.; Zhang, Y. Monodisperse silica-coated polyvinylpyrrolidone $\mathrm{NaYF}_{4}$ nanocrystals with multicolor upconversion fluorescence emission. Angew. Chem. Int. Ed. 2006, 45, 7732-7735.

14. Liu, Q.; Li, C.; Yang, T.; Yi, T.; Li, F. "Drawing" upconversion nanophosphors into water through host-guest interaction. Chem. Commun. 2010, 46, 5551-5553.

15. Liu, Q.; Chen, M.; Sun, Y.; Chen, G.; Yang, T.; Gao, Y.; Zhang, X.; Li, F. Multifunctional rare-earth self-assembled nanosystem for tri-modal upconversion luminescence/fluorescence/ positron emission tomography imaging. Biomaterials 2011, 32, 8243-8253.

16. Liu, Q.; Sun, Y.; Li, C.; Zhou, J.; Li, C.; Yang, T.; Zhang, X.; Yi, T.; Wu, D.; Li, F. 18F-labeled magnetic-upconversion nanophosphors via rare-earth cation-assisted ligand assembly. ACS Nano 2011, 5, 3146-3157.

17. Wang, X.; Zhuang, J.; Peng, Q.; Li, Y. A general strategy for nanocrystal synthesis. Nature 2005, 437, 121-124.

18. Jalil, R.A.; Zhang, Y. Biocompatibility of silica coated $\mathrm{NaYF}_{4}$ upconversion fluorescent nanocrystals. Biomaterials 2008, 29, 4122-4128.

19. Guo, H.; Qian, H.; Idris, N.M.; Zhang, Y. Singlet oxygen induced apoptosis of cancer cells using upconversion fluorescent nanoparticles as a carrier of photosensitizer. Nanomedicine 2010, 6 , 484-495.

20. Li, Z.; Wang, L.; Wang, Z.; Liu, X.; Xiong, Y. Modification of $\mathrm{NaYF}_{4}: \mathrm{Yb}, \mathrm{Er}_{\mathrm{S}} \mathrm{SiO}_{2}$ nanoparticles with gold nanocrystals for tunable green to red upconversion emission. J. Phys. Chem. C 2011, 115, 3291-3296.

21. Liu, Q.; Sun, Y.; Yang, T.; Feng, W.; Li, C.; Li, F. Sub-10 nm hexagonal lanthanide-doped $\mathrm{NaLuF}_{4}$ upconversion nanocrystals for sensitive bioimaging in vivo. J. Am. Chem. Soc. 2011, $133,17122-17125$.

22. Lim, S.F.; Riehn, R.; Ryu, W.S.; Khanarian, N.; Tung, C.; Tank, D.; Austin, R.H. In vivo and scanning electron microscopy imaging of upconverting nanophosphors in caenorhabditis elegans. Nano Lett. 2006, 6, 169-174. 
23. Xiong, L.; Chen, Z.; Tian, Q.; Cao, T.; Xu, C.; Li, F. High contrast upconversion luminescence targeted imaging in vivo using peptide-labeled nanophosphors. Anal. Chem. 2009, 81, 8687-8694.

24. Lin, C.; Berry, M.T.; Anderson, R.; Smith, S.; May, P.S. Highly luminescent NIR-to-visible upconversion thin films and monoliths requiring no high-temperature treatment. Chem. Mater. 2009, 21, 3406-3413.

25. Yi, G.; Lu, H.; Zhao, S.; Ge, Y.; Yang, W.; Chen, D.; Guo, L. Synthesis, characterization, and biological application of size-controlled nanocrystalline $\mathrm{NaYF}_{4}: \mathrm{Yb}, \mathrm{Er}$ infrared-to-visible up-conversion phosphors. Nano Lett. 2004, 4, 2191-2196.

26. Heer, S.; Kompe, K.; Gvdel, H.U.; Haase, M. Highly efficient multicolour upconversion emission in transparent colloids of lanthanide-doped $\mathrm{NaYF}_{4}$ nanocrystals. Adv. Mater. 2004, 16, 2102-2105.

27. Mai, H.; Zhang, Y.; Sun, L.; Yan, C. Size- and phase-controlled synthesis of monodisperse $\mathrm{NaYF}_{4}: \mathrm{Yb}, \mathrm{Er}$ nanocrystals from a unique delayed nucleation pathway monitored with upconversion spectroscopy. J. Phys. Chem. C 2007, 111, 13730-13739.

28. Mai, H.X.; Zhang, Y.W.; Si, R.; Yan, Z.G.; Sun, L.D.; You, L.P.; Yan, C.H. High-quality sodium rare-earth fluoride nanocrystals: Controlled synthesis and optical properties. J. Am. Chem. Soc. 2006, 128, 6426-6436.

29. Boyer, J.C.; Vetrone, F.; Cuccia, L.A.; Capobianco, J.A. Synthesis of colloidal upconverting $\mathrm{NaYF}_{4}$ nanocrystals doped with $\mathrm{Er}^{3+}, \mathrm{Yb}^{3+}$ and $\mathrm{Tm}^{3+}, \mathrm{Yb}^{3+}$ via thermal decomposition of lanthanide trifluoroacetate precursors. J. Am. Chem. Soc. 2006, 128, 7444-7445.

30. Boyer, J.-C.; Cuccia, L.A.; Capobianco, J.A. Synthesis of colloidal upconverting NaYF $4: \mathrm{Er}^{3+} / \mathrm{Yb}^{3+}$ and $\mathrm{Tm}^{3+} / \mathrm{Yb}^{3+}$ monodisperse nanocrystals. Nano Lett. 2007, 7, 847-852.

31. Yi, G.; Sun, B.; Yang, F.; Chen, D.; Zhou, Y.; Cheng, J. Synthesis and characterization of high-efficiency nanocrystal up-conversion phosphors: Ytterbium and erbium codoped lanthanum molybdate. Chem. Mater. 2002, 14, 2910-2914.

32. Zeng, J.H.; Su, J.; Li, Z.H.; Yan, R.X.; Li, Y.D. Synthesis and upconversion luminescence of hexagonal-phase $\mathrm{NaYF}_{4}: \mathrm{Yb}_{\mathrm{Er}}{ }^{3+}$ phosphors of controlled size and morphology. Adv. Mater. 2005, 17, 2119-2123.

33. Taylor, J.R.; Fang, M.M.; Nie, S. Probing specific sequences on single DNA molecules with bioconjugated fluorescent manoparticles. Anal. Chem. 2000, 72, 1979-1986.

34. Wei, Y.; Lu, F.; Zhang, X.; Chen, D. Synthesis of oil-dispersible hexagonal-phase and hexagonal-shaped $\mathrm{NaYF}_{4}$ :Yb,Er nanoplates. Chem. Mater. 2006, 18, 5733-5737.

35. Fan, X.; Pi, D.; Wang, F.; Qiu, J.; Wang, M. Hydrothermal synthesis and luminescence behavior of lanthanide-doped $\mathrm{GdF}_{3}$ nanoparticles. Trans. Nanotechnol. 2006, 5, 123-128.

36. Zhang, F.; Wan, Y.; Yu, T.; Zhang, F.; Shi, Y.; Xie, S.; Li, S.; Li, Y.; Xu, L.; Tu, B.; Zhao, D. Uniform nanostructured arrays of sodium rare-earth fluorides for highly efficient multicolor upconversion luminescence. Angew. Chem. Int. Ed. 2007, 46, 7976-7979.

37. Li, C.; Yang, J.; Quan, Z.; Yang, P.; Kong, D.; Lin, J. Different microstrutures of $\mathrm{NaYF}_{4}$ fabricated by hydrothermal process: Effects of $\mathrm{pH}$ values and fluoride sources. Chem. Mater. 2007, 19, 4933-4942. 
38. Li, C.; Quan, Z.; Yang, J.; Yang, P.; Lin, J. Highly uniform and monodisperse $\beta-\mathrm{NaYF}_{4}: \mathrm{Ln}^{3+}$ synthesis and luminescent properties. Inorg. Chem. 2007, 46, 6329-6337.

39. Wang, L.; Li, Y. $\mathrm{NaY}_{1.5} \mathrm{Na}_{0.5} \mathrm{~F}_{6}$ single crystal nanorods as multicolor luminescent material. Nano Lett. 2006, 6, 1645-1649.

40. Liu, X.; Zhao, J.; Sun, Y.; Song, K.; Yu, Y.; Du, C.; Kong, X.; Zhang, H. Ionothermal synthesis of hexagonal-phase $\mathrm{NaYF}_{4}: \mathrm{Yb}^{3+}, \mathrm{Er}^{3+} / \mathrm{Tm}^{3+}$ upconversion nanophosphors. Chem. Commun. 2009, 6628-6630.

41. Sandrock, T.; Scheife, H.; Heumann, E.; Huber, G. High-power continuous-wave upconversion fiber laser at room temperature. Opt. Lett. 1997, 22, 808-810.

42. Shalav, A.; Richards, B.S.; Trupke, T. Application of $\mathrm{NaYF}_{4}: \mathrm{Er}^{3+}$ upconversion phosophors for enhanced near-infrared silicon solar cell response. Appl. Phys. Lett. 2005, 86, 13503-13505.

43. Ivanova, S.; Pelle, F. Evaluation upconversion materials developed to improve the efficiency of solar cells: Reply to comment. J. Opt. Soc. Am. B 2010, 27, 1356-1358.

44. Kik, P.G.; Polman, A. Cooperative upconversion as the gain-limiting factor in Er doped miniature $\mathrm{Al}_{2} \mathrm{O}_{3}$ optical waveguide amplifiers. J. Appl. Phys. 2003, 93, 5008-5012.

45. Strohhofer, C.; Polman, A. Relationship between gain and $\mathrm{Yb}^{3+}$ concentration in $\mathrm{Er}^{3+}-\mathrm{Yb}^{3+}$ doped waveguide amplifiers. J. Appl. Phys. 2001, 90, 4314-4320.

46. Zhou, Z.; Hu, H.; Yang, H.; Yi, T.; Huang, K.; Yu, M.; Li, F.; Huang, C. Up-conversion luminescent switch based on photochromic diarylethene and rare earth nanophosphors. Chem. Commun. 2008, 4786-4788.

47. Zhang, C.; Zhou, H.; Liao, L.; Feng, W.; Sun, W.; Li, Z.; Xu, C.; Fang, C.; Sun, L.; Zhang, Y.; Yan, C. Luminescence modulation of ordered upconversion nanopatterns by a photochromic diarylethene: Rewritable optical storage with nondestructive readout. Adv. Mater. 2010, 22, 633-637.

48. Zijlmans, H.J.M.A.A.; Bonnet, J.; Burton, J.; Kardos, K.; Vail, T.; Niedbala, R.S.; Tanke, H.J. Detection of cell and tissue surface antigens using up-converting phosphors: A new reporter technology. Anal. Biochem. 1999, 267, 30-36.

49. Kuningas, K.; Rantanen, T.; Karhunen, U.; Lövgren, T.; Soukka, T. Simultaneous use of time-resolved fluorescence and anti-stokes photoluminescence in a bioaffinity assay. Anal. Chem. 2005, 77, 2826-2834.

50. Rantanen, T.; Järvenpää, M.-L.; Vuojola, J.; Kuningas, K.; Soukka, T. Fluorescence-quenchingbased enzyme-activity assay by using photon upconversion. Angew. Chem. Int. Ed. 2008, 47, 3811-3813.

51. Rantanen, T.; Päkkilä, H.; Jämsen, L.; Kuningas, K.; Ukonaho, T.; Lövgren, T.; Soukka, T. Tandem dye acceptor used to enhance upconversion fluorescence resonance energy transfer in homogeneous assays. Anal. Chem. 2007, 79, 6312-6318.

52. van de Rijke, F.; Zijlmans, H.; Li, S.; Vail, T.; Raap, A.K.; Niedbala, R.S.; Tanke, H. Up-converting phosphor reporters for nucleic acid microarrays. Nature 2001, 19, 273-276.

53. Lim, S.F.; Riehn, R.; Tung, C.; Ryu, W.S.; Zhuo, R.; Dalland, J.; Austin, R.H. Upconverting nanophosphors for bioimaging. Nanotechnology 2009, 20, 405701-405707. 
54. Hilderbrand, S.A.; Shao, F.W.; Salthouse, C.; Mahmood, U.; Weissleder, R. Upconverting luminescent nanomaterials: Application to in vivo bioimaging. Chem. Commun. 2009, doi: 10.1039/B905927J.

55. Chatterjee, D.K.; Rufaihah, A.J.; Zhang, Y. Upconversion fluorescence imaging of cells and small animals using lanthanide doped nanocrystals. Biomaterials 2008, 29, 937-943.

56. Xiong, L.; Yang, T.; Yang, Y.; Xu, C.; Li, F. Long-term in vivo biodistribution imgaing and toxicity of polyacrylic acid-coated upconversion nanophosphors. Biomaterials 2010, 31, 7078-7085.

57. Daniell, M.D.; Hill, J.S. A history of photodynamic theray. Aust. NZ J. Surg. 1991, 61, 340-348.

58. Ackroyd, R.; Kelty, C.; Brown, N.; Reed, M. The history of photodetection and photodynamic therapy. Photochem. Photobiol. 2001, 74, 656-669.

59. Raab, O. Uber die wirkung fluoreszierender stoffe auf infusorien. Zeitung Biol. 1900, 39, 524-526.

60. Sharman, W.M.; Allen, C.M.; van Lier, J.E. Role of activated oxygen species in photodynamic theray. Meth. Enzymol. 2000, 319, 376-400.

61. Oleinick, N.L.; Morris, R.L.; Belichenko, T. The role of apoptosis in response to photodynamic therapy: What, where, why, and how. Photochem. Photobiol. Sci. 2002, 1, 1-21.

62. Dougherty, T.J.; Gomer, C.J.; Henderson, B.W.; Jori, G.; Kessel, D.; Korbelik, M.; Moan, J.; Peng, Q. Photodynamic therapy. J. Natl. Cancer Inst. 1998, 90, 889-905.

63. Brown, S.B.; Brown, E.A.; Walker, I. The present and future role of photodynamic therapy in cancer treatment. Lancet Oncol. 2004, 5, 497-508.

64. Dougherty, T.J. An update on photodynamic therapy applications. J. Clin. Laser. Med. Surg. 2002, 20, 3-7.

65. Stummer, W.; Hassan, A.; Kempski, O.; Goetz, C. Photodynamic therapy within edematous brain tissue: considerations on sensitizer dose and time point of laser irradiation. J. Photochem. Photobiol. B 1996, 36, 179-181.

66. Asadishad, B.; Vossoughi, M.; Alemzadeh, I. Folate-receptor-targeted delivery of doxorubicin using polyethylene glycol-functionalized gold nanoparticles. Ind. Eng. Chem. Res. 2010, 49, 1958-1963.

67. Brown, S.D.; Nativo, P.; Smith, J.A.; Stirling, D.; Edwards, P.R.; Venugopal, B.; Flint, D.J.; Plumb, J.A.; Graham, D.; Wheate, N.J. Gold nanoparticles for the improved anticancer drug delivery of the active component of oxaliplatic. J. Am. Chem. Soc. 2010, 132, 4678-4684.

68. Jang, B.; Park, J.Y.; Tung, C.H.; Kim, I.H.; Choi, Y. Gold nanorod photosensitizer complex for near infrared fluorescence imaging and photodynamic/photothermal therapy in vivo. ACS Nano 2011, 5, 1086-1094.

69. Ratanatawanate, C.; Chyao, A.; Balkus, K.J. S-nitrosocysteine decorated PbS QDs/TiO 2 nanotubes for enhanced production of singlet oxygen. J. Am. Chem. Soc. 2011, 133, 3492-3497.

70. Hsieh, J.M.; Ho, M.L.; Wu, P.W.; Chou, P.T.; Tsaih, T.T.; Chi, Y. Iridium-complex modified $\mathrm{CdSe} / \mathrm{ZnS}$ quantum dots: A conceptural design for bifunctionality toward imaging and phtoosensitization. Chem. Commun. 2006, doi: 10.1039/B517368J. 
71. Tsay, J.M.; Trzoss, M.; Shi, L.X.; Kong, X.X.; Selke, M.; Jung, M.E.; Weiss, S. Singlet oxygen production by peptide-coated quantum dot-photosensitizer conjugates. J. Am. Chem. Soc. 2007, 129, 6865-6871.

72. Samia, A.C.S.; Chen, X.B.; Burda, C. Semiconductor quantum dots for photodynamic therapy. J. Am. Chem. Soc. 2003, 125, 15736-15737.

73. Shi, L.X.; Hernandez, B.; Selke, M. Signlet oxygen generation from water-soluble quantum dot-organic dye nanocomposites. J. Am. Chem. Soc. 2006, 128, 6278-6279.

74. Shen, X.; He, F.; Wu, J.; Xu, G.; Yao, S.Q.; Xu, Q. Enhanced two photon singlet oxygen genergation by photosensitizer doped conjugated polymer nanoparticles. Langmuir 2011, 27, 1739-1744.

75. Chen, Z.; Chen, H.; Hu, H.; Yu, M.; Li, F.; Zhang, Q.; Zhou, Z.; Yi, T.; Huang, C. Versatile synthesis strategy for carboxylic acid-functionalized upconverting nanophosphors as biological labels. J. Am. Chem. Soc. 2008, 130, 3023-3029.

76. Chatterjee, D.K.; Zhong, Y. Upconversion nanoparticles as nanotransducers for photodynamic therapy in cancer cells. Nanomedicine 2008, 3, 73-82.

77. Qian, H.S.; Guo, H.C.; Ho, P.C.L.; Mahendran, R.; Zhang, Y. Mesoporous-silica-coated up-conversion fluorescent nanoparticles for photodynamic therapy. Small 2009, 5, 2285-2290.

78. Zhang, P.; Steelant, W.; Kumar, M.; Scholfield, M. Versatile photosensitizers for photodynamic therapy at infrared excitation. J. Am. Chem. Soc. 2007, 129, 4526-4527.

79. Medintz, I.L.; Uyeda, H.T.; Goldman, E.R.; Mattoussin, H. Quantum dot bioconjugates fro imaging, labeling, and sensing. Nat. Mater. 2005, 4, 435-446.

80. Michalet, X.; Pinaud, F.F.; Bentolila, L.A.; Tsay, J.M.; Doose, S.; Li, J.J.; Sundaresan, G.; Wu, A.M.; Gambhir, S.S.; Weiss, S. Quantum dots for live cells, in vivo imaging, and diagnostics. Science 2005, 307, 538-544.

81. Ow, H.; Larson, D.R.; Srivastava, M.; Baird, B.A.; Webb, W.W.; Wiesner, U. Bright and stable core-shell fluorescent silica nanoparticles. Nano Lett. 2005, 5, 113-117.

82. O’Connell, M.J.; Bachilo, S.M.; Huffman, C.B.; Moore, V.C.; Strano, M.S.; Haroz, E.H.; Rialon, K.L.; Boul, P.J.; Noon, W.H.; Kittrell, C.; Ma, J.; Hauge, R.H.; Weisman, R.B.; Smalley, R.E. Band gap fluorescence from individual single-walled carbon nanotubes. Science 2002, 297, 593-596.

83. Wang, F.; Liu, X. Upconversion multicolor fine-tuning: Visible to near-infrared emission from lanthanide-doped $\mathrm{NaYF}_{4}$ nanoparticles. J. Am. Chem. Soc. 2008, 130, 5642-5643.

84. Xiong, L.-Q.; Chen, Z.-G.; Yu, M.-X.; Li, F.-Y.; Liu, C.; Huang, C.-H. Synthesis, characterization, and in vivo targeted imaging of amine-functionalized rare-earth up-converting nanophosphors. Biomaterials 2009, 30, 5592-5600.

85. Zhou, J.-C.; Yang, Z.-L.; Dong, W.; Tang, R.-J.; Sun, L.-D.; Yan, C.-H. Bioimaging and toxicity assessments of near-infrared upconversion luminescent $\mathrm{NaYF}_{4}: \mathrm{Yb}, \mathrm{Tm}$ nanocrystals. Biomaterials 2011, 32, 9059-9067.

86. Cheng, L.; Yang, K.; Shao, M.; Lee, S.T.; Liu, Z. Multicolor in vivo imaging of upconversion nanoparticles with emissions tuned by luminescence resonance energy transfer. J. Phys. Chem. C 2011, 115, 2686-2692. 
87. Ryu, J.; Park, H.Y.; Kim, K.; Kim, H.; Yoo, J.H.; Kang, M.; Im, K.; Grailhe, R.; Song, R. Facile synthesis of ultrasmall and hexagonal $\mathrm{NaGdF}_{4}: \mathrm{Yb}^{3+}, \mathrm{Er}^{3+}$ nanoparticles with magnetic and upconversion imaging properties. J. Phys. Chem. C 2010, 114, 21077-21082.

88. Park, Y.; Kim, J.H.; Taek, L.K.; Jeon, K.S.; Na, H.B.; Yu, J.H.; Kim, H.M.; Lee, N.; Choi, S.H.; Baik, S.; Kim, H.; Park, S.P.; Park, B.J.; Kim, Y.W.; Lee, S.H.; Yoon, S.Y.; Song, I.C.; Moon, K.K.; Suh, Y.D.; Hyeon, T. Nonblinking and nonbleaching upconverting nanoparticles as an optical imaing nanoprobe and T1 magnetic resonance imaging contrast agent. Adv. Mater. 2009, 21, 4467-4471.

89. Yu, M.; Li, F.; Chen, Z.; Hu, H.; Zhan, C.; Yang, H.; Huang, C. Laser scanning up-conversion luminescence microscopy for imaging cells labeled with rare-earth nanophosphors. Anal. Chem. 2009, 81, 930-935.

90. Wu, S.; Han, G.; Milliron, D.J.; Aloni, S.; Altoe, V.; Talapin, D.V.; Cohen, B.E.; Schuck, P.J. Non-blinking and photostable upconverted luminescence from single lanthanide doped nanocrystals. PNAS 2009, 106, 10917-10921.

91. Kim, F.; Song, J.H.; Yang, P. Photochemical synthesis of gold nanorods. J. Am. Chem. Soc. 2002, 124, 14316-14317.

92. Schwartzberg, A.M.; Olson, T.Y.; Talley, C.E.; Zhang, J.Z. Synthesis, characterization, and tunable optical properties of hollow gold nanospheres. J. Phys. Chem. B 2006, 110, 19935-19944.

93. Wiley, B.J.; Chen, Y.; McLellan, J.M.; Xiong, Y.; Li, Z.Y.; Ginger, D.; Younan, X. Synthesis and optical properties of silver nanobars and nanorice. Nano Lett. 2007, 7, 1032-1036.

94. Tao, A.; Sinsermsuksakul, P.; Yang, P. Tunable plasmonic lattices of silver nanocrystals. Nat. Nanotechnol. 2007, 2, 435-440.

95. Lin, W.; Weihong, T. Multicolor FRET silica nanoparticles by single wavelength excitation. Nano Lett. 2006, 6, 84-88.

96. Han, M.; Gao, X.; Su, J.Z.; Nie, S. Quantum-dot-tagged microbeads for multiplexed optical coding of biomolecules. Nat. Nanotechnol. 2001, 19, 631-635.

97. Niu, W.; Wu, S.; Zhang, S.; Li, J.; Li, L. Multicolor output and shape controlled synthesis of lanthanide ion doped fluorides upconversion nanoparticles. Dalton Trans. 2011, 40, 3305-3314.

98. Mai, H.X.; Zhang, Y.-W.; Sun, L.-D.; Yan, C.-H. Highly efficient multicolor up-conversion emissions and their mechanisms of monodisperse $\mathrm{NaYF}_{4}: \mathrm{Yb}, \mathrm{Er}$ core and core/shell-structured nanocrystals. J. Phys. Chem. C 2007, 111, 13721-13729.

99. Ehlert, O.; Thomann, R.; Darbandi, M.; Nann, T. A four-color colloidal multiplexing nanoparticle system. ACS Nano 2008, 2, 120-124.

100. Li, Z.; Zhang, Y.; Jiang, S. Multicolor core/shell-structured upconversion fluorescent nanoparticles. Adv. Mater. 2008, 20, 4765-4769.

101. Zhang, H.; Li, Y.; Ivanov, I.A.; Qu, Y.; Duan, X. Plasmonic modulation of the upconversion fluorescence in $\mathrm{NaYF}_{4}: \mathrm{Yb} / \mathrm{Tm}$ hexaplate nanocrystals using gold nanoparticles or nanoshells. Angew. Chem. Int. Ed. 2010, 49, 2865-2868.

102. Li, D.; Dong, B.; Bai, X.; Wang, Y.; Song, H. Influence of the TGA modification on upconversion luminescence of hexagonal phase $\mathrm{NaYF}_{4}: \mathrm{Yb}^{3+}, \mathrm{Er}^{3+}$ Nanoparticles. J. Phys. Chem. C 2010, 114, 8219-8226. 
103. Huang, Q.; Yu, J.; Ma, E.; Lin, K. Synthesis and characterization of highly efficient near infrared upconversion $\mathrm{Sc}^{3+} / \mathrm{Er}^{3+} / \mathrm{Yb}^{3+}$ tridoped $\mathrm{NaYF}_{4}$. J. Phys. Chem. C 2010, 114, 4719-4724.

104. Chen, G.; Ohulchanskyy, T.; Kumar, R.; Agren, H.; Prasad, P.N. Ultrasmall monodisperse $\mathrm{NaYF}_{4}: \mathrm{Yb}^{3+} / \mathrm{Tm}^{3+}$ nanocrystals with enhanced near infrared to near infrared upconversion photoluminescence. ACS Nano 2010, 4, 3163-3168.

105. Bi, S.; Zhang, J.; Zhang, S. Ultrasensitive and selective DNA detection based on nicking endonuclease assisted signal amplification and its application in cancer cell detection. Chem. Commun. 2010, 46, 5509-5511.

106. Song, J.; Li, Z.; Cheng, Y.; Liu, C. Self aggregation of oligonucleotide functionalized gold nanoparticles and its applications for highly sensitive detection of DNA. Chem. Commun. 2010, 46, 5548-5550.

107. Li, H.; Rothberg, L.J. Label free colorimetric detection of specific sequences in genomic DNA amplified by the polymerase chain reaction. J. Am. Chem. Soc. 2004, 126, 10958-10961.

108. Rho, S.; Kim, S.J.; Lee, S.C.; Chang, J.H.; Kang, H.-G.; Choi, J. Colorimetric detection of ssDNA in a solution. Curr. Appl. Phys. 2009, 9, 534-537.

109. Corstjens, P.L.A.M.; Zuiderwijk, M.; Nilsson, M.; Feindt, H.; Niedbala, R.S.; Tanke, H.J. Lateral-flow and up-converting phosphor reporters to detect single-stranded nucleic acids in a sandwich-hydridization assay. Anal. Biochem. 2003, 312, 191-200.

110. Zhang, P.; Rogelj, S.; Nguyen, K.; Wheeler, D. Design of a highly sensitive and specific nucleotide sensor based on photon upconverting particles. J. Am. Chem. Soc. 2006, 128, 12410-12411.

111. Liu, C.; Wang, Z.; Jia, H.; Li, Z. Efficient fluorescence resonance energy transfer between upconversion nanophosphors and graphene oxide: A highly sensitive biosensing platform. Chem. Commun. 2011, 47, 4661-4663.

112. Mader, H.S.; Wolfbeis, O.S. Optical ammonia sensor based on upconverting luminescent nanoparticles. Anal. Chem. 2010, 82, 5002-5004.

113. Achatz, D.; Meier, R.J.; Fischer, L.H.; Wolfbeis, O.S. Luminescent sensing of oxygen using a quenchable probe and upconverting nanoparticles. Angew. Chem. Int. Ed. 2011, 50, 260-263.

114. Liu, J.; Liu, Y.; Liu, Q.; Li, C.; Sun, L.; Li, F. Iridium(III) complex-coated nanosystem for ratiometric upconversion luminescence bioimaging of cyanide anions. J. Am. Chem. Soc. 2011, $133,15276-15279$.

115. Liu, Q.; Peng, J.; Sun, L.; Li, F. High-efficiency upconversion luminescent sensing and bioimaging of $\mathrm{Hg}$ (II) by chromophoric ruthenium complex-assembled nanophosphors. ACS Nano 2011, 5, 8040-8048.

(C) 2012 by the authors; licensee MDPI, Basel, Switzerland. This article is an open access article distributed under the terms and conditions of the Creative Commons Attribution license (http://creativecommons.org/licenses/by/3.0/). 